\title{
Melampus and the cure of Proetus' daughters
}

\author{
Vasiliki Vasileiou, ${ }^{1}$ Georgios K. Markantes, ${ }^{2}$ Anastasia K. Armeni, ${ }^{2}$ \\ Konstantina Barouti, ${ }^{2}$ Angeliki Georgopoulou, ${ }^{2}$ Neoklis A. Georgopoulos ${ }^{2}$
}

\begin{abstract}
${ }^{1} 1^{\text {st }}$ Department of Endocrinology, Diabetes Centre, "Alexandra" Hospital, Athens, Greece; 2Division of Reproductive Endocrinology, Department of Obstetrics and Gynecology, University of Patras Medical School, Patras, Greece
\end{abstract}

Dear Editor,

In Greek mythology, Melampus, son of Amythaon was a seer and healer. His name means "black foot" or "man with the black feet" as, according to the legend, when he was a neonate he was left by his mother with his feet exposed to the bright sun. Being the Greek prototype of the shaman, he was, according to Herodotus, the introducer of the worship of Dionysus and the creator of an entire school of magic healers known as the Melampodians. He became the ruler of Argos after curing the daughters of Proetus, king of Tiryns, of insanity (Figure 1). At Argos, Melampus was held to be the first priest of Dionysus and originator of mysterious customs at ecstatic festivals and ceremonies of expiation. He is supposed to have lived at the dawn of the Mycenaean era, i.e. around $1600 \mathrm{BC}$, his lineage lasting down to the brothers Alcmaeon and Amphilochus, who fought in the Trojan War (c. 1200 BC). ${ }^{1}$

Key words: Addison's, Cushing's, Ergotism, Glycyrrhiza glabra, Helleborus niger, Liquorice, Melampus, Proetus

\footnotetext{
Address for correspondence:

Neoklis A. Georgopoulos, Department of Obstetrics and Gynecology, Division of Reproductive Endocrinology, University of Patras Medical School, Rio-26500, Patras, Greece; Tel: +30 2610-999835, Fax: +30 2610-993854,

E-mail: neoklisg@hol.gr

Received: 16-05-2017, Accepted: 19-05-2017
}

\section{The myth}

The daughters of Proetus, Lysippe, Iphinoe and Iphianassa, were seized with manic madness because they despised the worship of Dionysus. They believed themselves to be cows and wandered in the wilderness, mooing, abominable in sight with bald head and skin turned white and covered with purulent wounds.

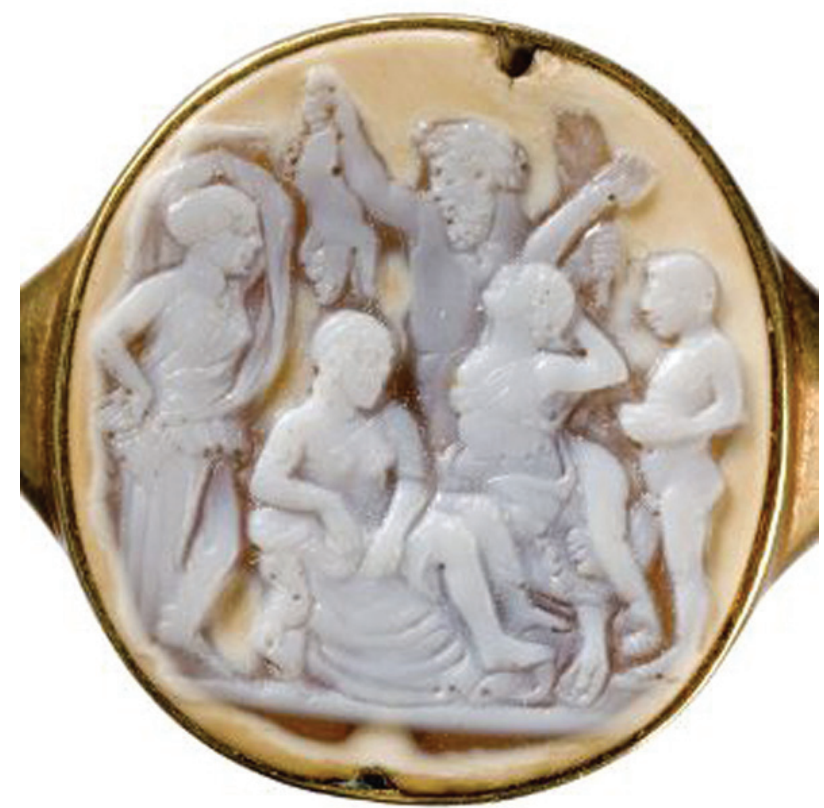

Figure 1. Ring with a stone inset in relief, 1st c. A.D. Melampus is depicted in the center background, holding aloft and upside down a branded swine and a laurel branch. He is purifying Proetus' daughters. Lysippe, Iphinoe and Iphianassa. With them are a young man and also a nymph of the springs, from which source water was used for the cleaning (Médailles et Antiques de la Bibliothèque Nationale de France). 
Their insanity manifested mainly as hypersexuality in the form of sexual attacks on male shepherds in the woods. Melampus promised to cure the women, if the king would give him one-third of his kingdom (Figure 2). Proetus refused the proposal but when the madness continued while also spreading to other women of Argos, Proetus called Melampus back. However, the seer now demanded two-thirds of the kingdom, one for himself, and the other for his brother Bias (denoting "violence"). The king felt he had no choice but to agree, and so Melampus chased the insane women through the woods, trapped them in a cave deep inside the mountains of Arcadia (today called "The Cave of Lakes" in Castria, Achaia) and healed them of their madness with sacred baths and the use of a herb called Helleborus niger (Figure 3 ). Lysippe died during the chase, but the other two women, Iphinoe and Iphianassa (the component "Iphi" signifies "power"), were brought back to Argos cured and were married to Melampus and Bias, who ruled the kingdom of Argos thereafter. ${ }^{2}$

\section{Medical Differential diagnosis}

The "madness" of Proetus daughters represents a very interesting medical case characterized by the acute onset of both psychiatric (disinhibition, sexual hyperactivity, mania, delirium) and dermatologic (alopecia, skin depigmentation and ulceration) symptoms in several individuals simultaneously. All the patients were inhabitants of the same area; furthermore, the successful treatment implemented by Melampus included isolation, a very specific diet, as well as the use of Helleborus niger, a herb with anti-psychotic and anti-depressant actions (among others).

The available clinical and demographic data argue in favor of poisoning or an infectious disease as the cause of the symptoms. The fact that with isolation and diet alone the vast majority of patients were completely cured makes ingestion of an exogenous substance, whether deliberate or unintentional, the most likely diagnosis.

If so, could Melampus, a famous shaman, be at the same time both the culprit and the healer of the madness by manipulating the use of several herbs? After all, the benefit of restoring the women's sanity was enormous: the crown of the kingdom of Argos.

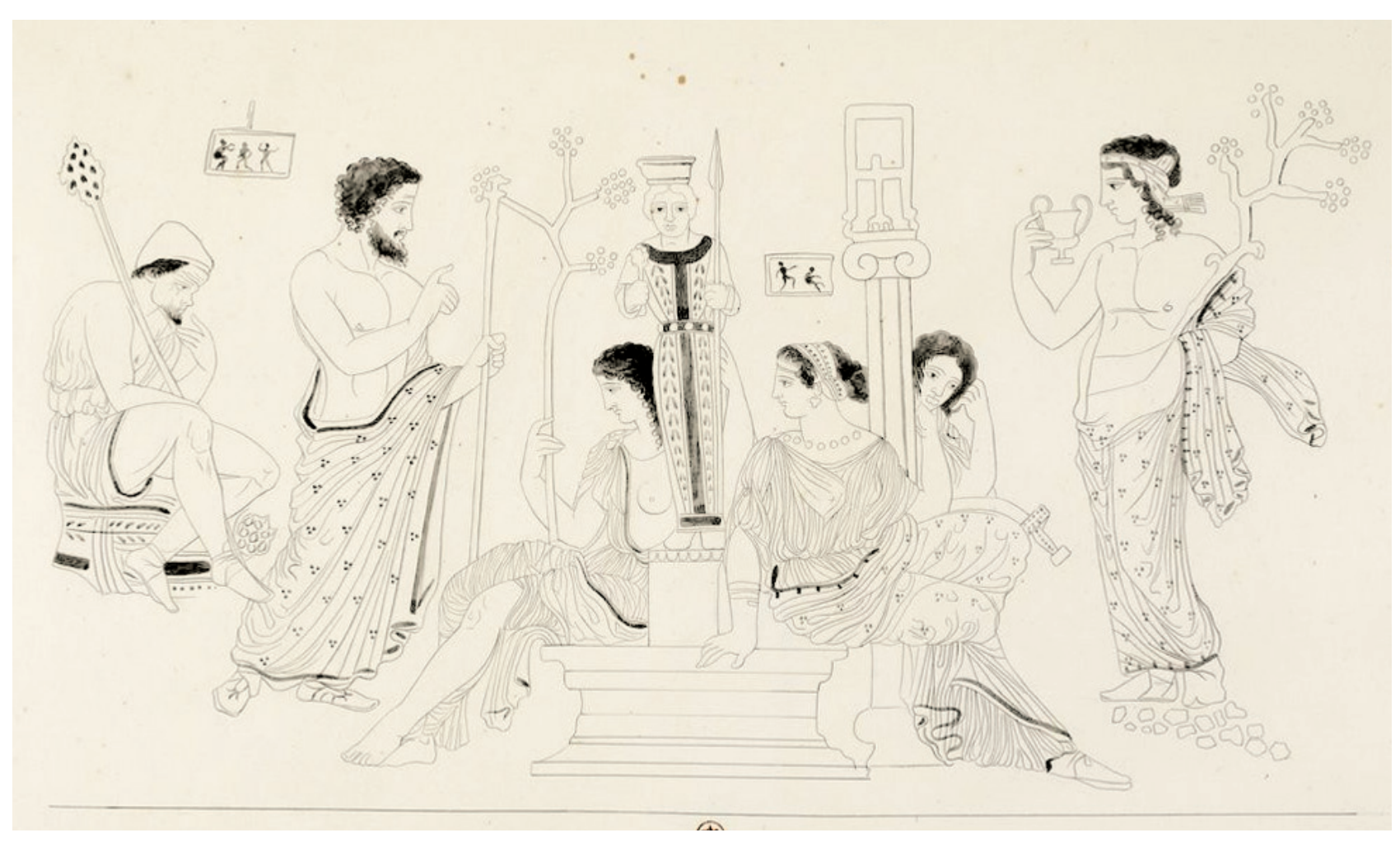

Figure 2. Melampus and Proetus at the temple of Artemis (Médailles et Antiques de la Bibliothèque Nationale de France). 


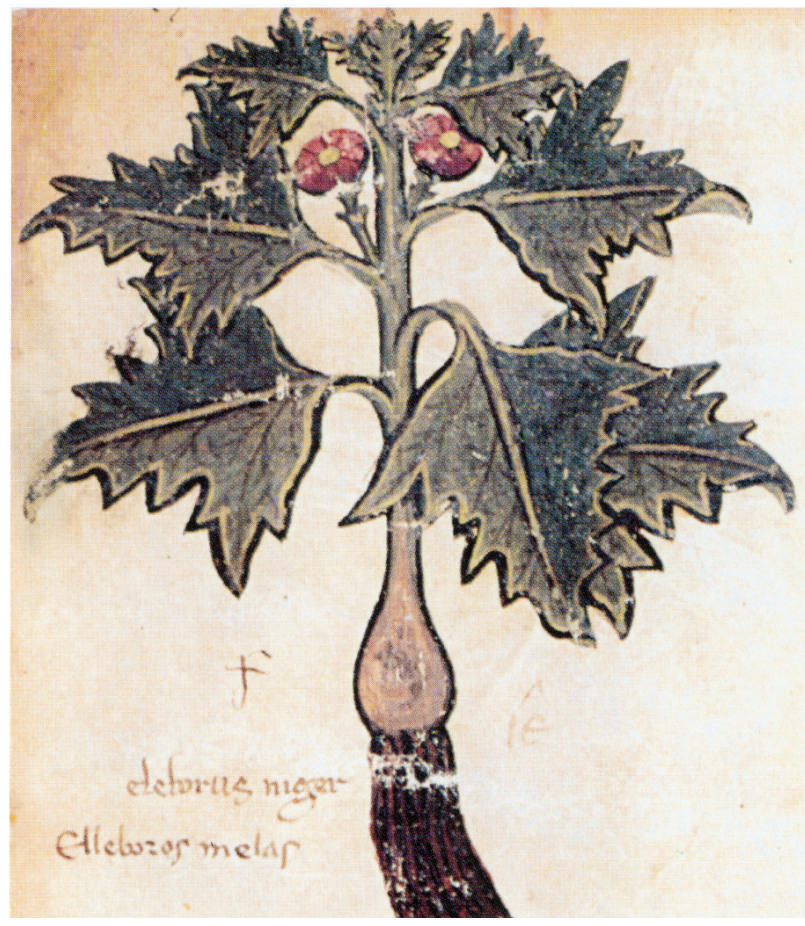

Figure 3. Helleborus niger.

\section{Ergotism}

Ergotism is one of the most fascinating foodborne diseases ever described. With a variety of debilitating and potentially fatal symptoms arising from many affected organ systems and its cause remaining elusive for centuries, it was responsible for the death of hundreds of thousands in medieval Europe.

Ergotism is in fact the effect of poisoning from the alkaloids produced by the fungus Claviceps purpurea. This fungus infects cereals, with a strong preference for rye, and produces a variety of alkaloids. The ergot alkaloids are structurally similar to biogenic amines (adrenaline, dopamine, and serotonin) and exert their biologic actions by binding with high affinity to their receptors.

Ergotism is traditionally divided into two forms: gangrenous and convulsive. Gangrenous ergotism is characterized by severe peripheral arterial vasoconstriction which manifests as paresthesia, burning limb pain ("ignis sacer"), loss of peripheral sensation, edema and skin desquamation, Raynaud's phenomenon and, finally, dry gangrene and autoamputation. In convulsive ergotism, symptoms arising from a derangement of the central nervous system prevail. There are involuntary twisting movements, tremor, myoclonus and even generalized seizures. Psychiatric symptoms like delirium and tactile hallucinations (formication) or even mania and psychosis may be observed. Concurrence of the two forms of ergotism has been reported, albeit rarely. ${ }^{3}$

A combination of convulsive and gangrenous ergotism caused by ingestion of contaminated rye or wheat flour could account for the clinical presentation of the women of Argos.

\section{Cushing's syndrome and liquorice}

The combination of mania, psychosis, hypersexuality, alopecia and dermatologic findings might also be the result of exposure to supranormal amounts of glucocorticoids and/or androgens.

Cushing's syndrome is characterized by chronic exposure to increased levels of endogenous or exogenous glucocorticoids. Clinical signs that appear to accord with our story include increased fat deposition on the neck ("buffalo hump"), thin skin with purple/ red striae and ulcers, dermatologic manifestations of hyperandrogenemia like acne, hirsutism and androgenic alopecia, as well as cognitive dysfunction, emotional instability, mania and psychosis.

As for the case under review, poisoning with a herb that contains glucocorticoid/androgen-like substances or increases the production and/or potentiates the action of the relevant endogenous hormones could explain the abovementioned phenotype.

Several plants have demonstrated androgenic activity in vitro or in vivo and some of them have been used to treat sexual dysfunction and infertility, especially by traditional Eastern medicine. Examples include Er-Xian decoction, Tulbaghia violacea, Trichosanthes kirilowii. Similarly, there are various herbs interfering with the hypothalamus-pituitary-adrenal (HPA) axis in a manner that leads to increased glucocorticoid activity, like Panax ginseng, Tylophora asthmatica and Cardiospermum halicacabum. However, none of the aforementioned herbs thrive in the geographical region where our story unfolds.

The only plant with a documented action on the HPA axis which is native to Southern Europe-and 
therefore to the area of interest, Greece-is Glycyrrhiza glabra (GG). GG is a herbaceous perennial legume whose root (liquorice) is used as a flavouring agent, but has also traditionally been used in numerous folk remedies. Even today, liquorice is a basic ingredient of many herbal medications, prescribed for various indications (skin diseases, peptic ulcer, erectile dysfunction etc). The main ingredients of liquorice are glycyrrhizin, anethole and the flavonoids glabrene and glabridin.

When ingested, glycyrrhizin is transformed by gut bacteria to glycyrrhetic acid, which is absorbed and further metabolised in the liver by sulfurylation and glucuronidation. The structure of glycyrrhetic acid is similar to that of cortisone and this might explain its anti-inflammatory action. 3- $\beta$-D-monoglucuronyl-18$\beta$-glycyrrhetinic acid inhibits the conversion of cortisol to "inactive" cortisone in the kidneys via inhibition of the enzyme 11- $\beta$-hydroxysteroid dehydrogenase type 2 (11 $\beta$-HSD2). This results in increased cortisol levels within the kidneys and therefore edema, hypertension, hypokalemia and metabolic alkalosis due to cross-reaction of cortisol with the mineralocorticoid receptor. ${ }^{4}$ Although it has been proven that liquorice does not act on the adrenals nor does it cause hypercortisolemia but exerts its mineralocorticoid action by simply affecting the renal handling of cortisol, recent identification of neurons in the nucleus of the solitary tract that express $11 \beta$-HSD2 and regulate sodium appetite might imply the existence of additional pathways by which $11 \beta$-HSD2 inactivation could lead to salt and water retention. Finally, studies regarding the effect of liquorice administration on androgens have produced controversial results, with some showing increased and other decreased levels. ${ }^{5}$

The flavonoid ingredients of liquorice are phytoestrogens exerting estrogenic effects on breast, vascular, and bone tissue. Glabrene is also a tyrosinase inhibitor which may cause skin blanching via inhibition of melanin formation in the epidermal melanocytes.

In conclusion, based on current knowledge, it is evident that ingestion of glycyrrhiza extracts can only partially explain the symptoms of Proetus' daughters. Still, since exogenous Cushing's syndrome is a plausible scenario in our case, the possibility of liquorice poisoning-alone or in combination with other agents that could enhance its actions-cannot be ruled out.

\section{Helleborus niger}

According to the myth, Melampus used the herb Helleborus niger to treat Proetus' daughters. Indeed, several writers confirm that the seer healer was the introducer of the use of Helleborus in ancient medicine. Helleborus niger is an evergreen plant of the family Ranunculaceae. The root and leaves of this plant contain the glucosides hellebore (cardiotoxic), helleborin (neurotoxic) and ranuncoside, steroid saponins and a variety of alkaloids. Helleborus niger has been used for centuries, from prehistoric times to the Middle Ages, as a medicine (cathartic, cardiac stimulant, diuretic, in the treatment of epilepsy, mania and depression, to induce abortion and to treat skin disorders). In large doses it is a powerful poison causing severe diarrhea and vomiting, heart failure, painful spasms, seizures and eventually death. ${ }^{6}$

Apparently, H. niger represented the perfect remedy for Proetus' daughters, as its active compounds were able to mitigate all their symptoms.

It is noteworthy that digoxin, another cardiac glucoside, has been shown to induce a decrease in ACTH-stimulated cortisol and aldosterone release in monkeys. Hence, if Cushing's syndrome was the cause of the symptoms, a glucoside-containing substance with the ability to suppress the HPA axis would represent the perfect antidote.

\section{Cultural, political, historical and philosophical aspects}

Greek mythology has been proven to be amazingly comprehensive as, besides the powerful imagery, it has numerous deep messages and meanings, each one addressed to a different audience. A myth is at once a retelling of historical events, a philosophical principle and a moral lesson. For example, the cure of Proetus' daughters by Melampus is firstly a description in the form of a legend of the Aeolic conquest of Argos overturning the previously ruling Semitic dynasty, a conquest achieved both peacefully, by the introduction of the cult of Dionysus, and violently, by the forced sharing of the kingdom with Bias. Secondly, it represents the first instance of shared rule between a shaman and a king in this region, reflected in historical times as the twin reign of Sparta by a 
religious and a military king. Finally, Melampus in the eyes of the simple people is the shaman with feet blackened from the burning sun, in the eyes of the healers he is the seer with feet blackened by the use of the herb Helleborus niger and, lastly, in the eyes of the followers of the mystic Dionysian cult, he is the initiated and ecstatic priest-king with the black phallus, the leader of the orgiastic ceremonies of Dionysus.

\section{REFERENCES}

1. Robert Graves 1955 The Greek Myths. Penguin Books Ltd, London; pp, 233-236.

2. Apollodorus 1854 Apollodori Bibliotheca Ex Recog- nitione Immanuelis Bekkeri. Sumptibus Et Typis B.G. Teubneri, Lipsiae; pp, 40-41.

3. Lapinskas V, 2007 A brief history of ergotism: From St. Anthony's fire and St. Vitus' dance until today. Medicinos Teorija ir Praktika 13: 202-206.

4. Epstein MT, Espiner EA, Donald RA, Hughes H, Cowles RJ, Lun S, 1978 Licorice raises urinary cortisol in man. J Clin Endocrinol Metab 47: 397-400.

5. Al-Dujaili EA, Kenyon CJ, Nicol MR, Mason JI, 2011 Liquorice and glycyrrhetinic acid increase DHEA and deoxycorticosterone levels in vivo and in vitro by inhibiting adrenal SULT2A1 activity. Mol Cell Endocrinol 336: 102-109.

6. Felter HW, Lloyd JU, 1898 Helleborus - Black Hellebore. In: Felter HW, Lloyd JU (eds) King's American Dispensatory. 